\title{
Concepções de educação e currículo em educação (a distância): Pressupostos teóricos para a construção de MEDS
}

Antonella Carvalho de Oliveira

Antonio Carlos Frasson

\begin{abstract}
Resumo
O objetivo deste trabalho é contribuir para a construção de Materiais Educacionais Digitais (MEDS) para a Educação a Distância (EAD) articulando as concepções de educação e currículo que permeiam o processo ensinoaprendizagem. Partiu-se da premissa neste estudo, que os MEDS são recursos digitais elaborados intencionalmente para favorecer a aprendizagem. Para fins de planejamento da pesquisa, foi levantado o seguinte problema de pesquisa: Como as concepções de educação e currículo presentes no processo ensinoaprendizagem contribui para a construção de MEDS? A conclusão aponta que é alta a importância da utilização da teoria histórico crítica para a construção de MEDS para a EAD. Indica também a viabilidade da utilização destas teorias para a ampliação e qualidade dos materiais, bem como o desvelamento das concepções que por muitas vezes são contraditórias com a prática e podem representar uma barreira para o alcance dos objetivos da educação, seja ela presencial ou não.
\end{abstract} digitais.

Palavras-chave: educação à distância, currículo, materiais educacionais

\section{Abstract}

The objective of this work is to contribute to the construction of Digital Educational Materials (DEM) for Distance Learning (DL) articulating the concepts of education and curriculum that permeate the learning process. Started from the premise in this study that the DEM are designed digital resources intentionally to promote learning. For search planning purposes, the following research problem was raised: How the concepts of education and curriculum present in the learning process contribute to the construction of DEM? The conclusion shows that the importance of using the historical critical theory to build DEM for DL is high. It also indicates the feasibility of using these theories to the expansion and quality of DEM, and the unveiling of the conceptions which often are contradictory with practice and may represent a barrier to achieving the goals of education, be it in person or not.

Keywords: distance education, curriculum, digital learning materials.

\section{Introdução}

Observando rapidamente, pode nos parecer que a escola e os professores perderam suas funções de construtores, mediadores e transmissores de conhecimentos. As intrinsecas mudanças

DOI: Em andamento. 
que estão se processando na contemporaneidade nos passam a impressão de que eles são prescindíveis e podem ser substituídos por equipamentos tecnológicos e computadores de última geração, através dos quais, seria possível ao educando adquirir conhecimento. Entretanto, "quando se buscam mudanças efetivas na sala de aula e na sociedade, de imediato se pensa no mestre tanto do ponto de vista didático pedagógico quanto político" (GASPARIN, 2005, p. 1). Isso leva a corrroborar a ideia defendida por Saviani (2011) quando considera que não interessa uma informação per se e sim uma informação mediada pedagogicamente.

É indiscutível que a Educação a Distância (EAD) vem ocasionando uma mudança significativa nas formas de perceber e avaliar o processo ensino-aprendizagem desde as últimas décadas do século passado. Essa modalidade de ensino passou a ser vista como um poderoso recurso para democratizar o acesso ao conhecimento e ampliar as oportunidades de aprendizagem ao longo da vida, como bem atestam os recentes investimentos públicos e privados nessa modalidade de ensino, que ocorrem desde a promulgação da Lei de Diretrizes e Bases da Educação Nacional (LDBEN/1996). Assiste-se, nos últimos tempos, ao desenvolvimento de uma infinidade de propostas didático-pedagógicas para a EAD. À medida que vão aparecendo no mercado novas tecnologias, elas vão sendo incorporadas ao sistema educacional, fazendo com que as questões de EAD sejam olhadas mais do ponto de vista tecnológico do que pedagógico. Isso traz resultados negativos, levando ao fracasso escolar, pois se colocam como foco as mudanças tecnológicas e não paradigmáticas (BEHAR, 2009, p. 24).

"Apesar da possibilidade de diferentes modos de organização, um ponto deve ser comum a todos aquele que desenvolvem projetos nessa modalidade: é a compreensão de EDUCAÇÃO como fundamento primeiro, antes de se pensar no modo de organização: A DISTÂNCIA. Assim, embora a modalidade a distância possua características, linguagem e formato próprios, exigindo administração, desenho, lógica, acompanhamento, avaliação, recursos técnicos, tecnológicos, de infraestrutura e pedagógicos condizentes, essas características só ganham relevância no contexto de uma discussão política e pedagógica da ação educativa (BRASIL, 2007, p. 7, grifo nosso)."

Contudo, para que essa modalidade de ensino conquiste definitivamente a credibilidade e a confiança da comunidade acadêmica ela precisa apresentar resultados iguais ou até mais significativos do que aqueles alcançados pelos cursos presenciais. Um dado importante, que não pode ser esquecido, é que a EAD não permite que se faça, via recursos tecnológicos, uma simples transposição do presencial e menos ainda, que sejam incorporados a EAD os erros do ensino presencial convencional: fragmentação dos conteúdos, excesso de memorização, hierarquia rígida entre professor e alunos e outros (SOUTO; PAIVA, 2013).

A EAD deve contar ainda com equipe multidisciplinar qualificada para preparação de materiais didáticos, professores capacitados para atuar nessa modalidade de ensino, recursos 
tecnológicos adequados, metodologia e processos de gestão e avaliação devidamente planejados e selecionados de modo a criar, para o estudante, as melhores condições de aprendizagem.

\section{Concepção de educação e currículo no processo de ensino- aprendizagem}

Para compreender a concepção de educação e currículo que permeiam o processo ensino- aprendizagem na EAD atualmente, é necessário recordar que a concepção de educação tradicional implantada no Brasil pelos Jesuítas, perdurou até o governo de Getúlio Vargas (1930), quando no Brasil começou o movimento Escolanovista, mantido até a Ditadura Militar (1964). No período compreendido entre 1974 e 1985 houve o movimento de abertura política, que culminou com o fim da Ditadura Militar e com a proclamação da nova constituição (SAVIANI, 2011). Essa abertura política deu início às teorias críticas e pós-criticas, conforme mostra a figura 1.

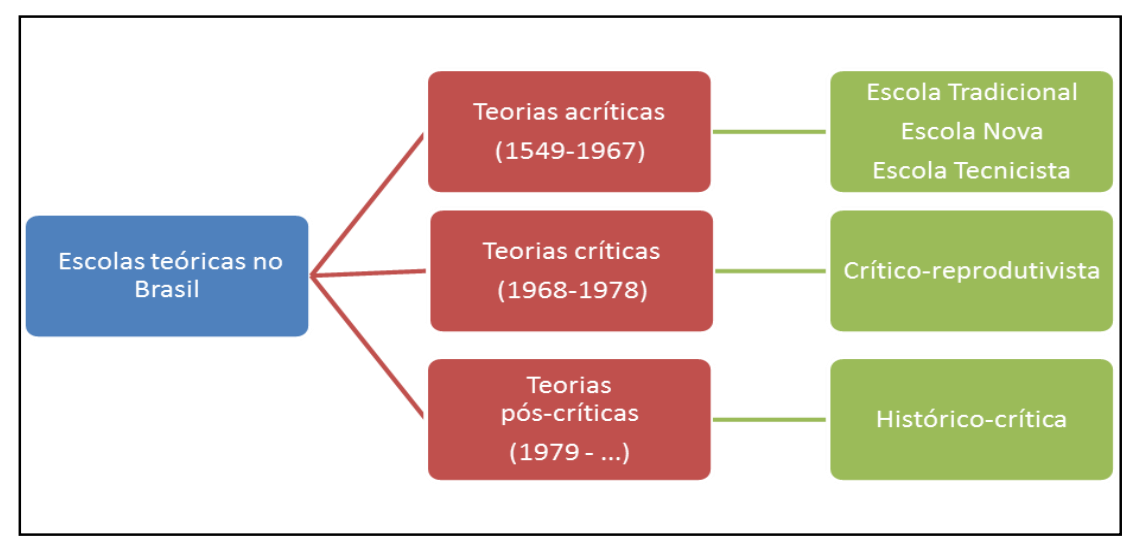

Figura 1 - Escolas teóricas no Brasil

Fonte: A autora (2014).

As concepções de educação embasadas nas escolas tradicional, escolanovista e tecnicista são chamadas de teorias acríticas, pois não exercem compromisso com as transformações sociais, avalizando o sistema econômico e social imposto, por meio de um currículo que privilegia a cultura da elite dominante. Visa formar o "indivíduo" para a manutenção do status quo, preparando-o para o desempenho das funções sociais de acordo com a casta social a que pertence (CUNHA; SOUZA, 2011).

As teorias críticas surgem delatando o poder da hegemonia dominante, cujos processos de adaptação, convencimento e perpetuação das desigualdades são corroborados pelas práticas escolares. Essa teoria visa formar um "sujeito" emancipado e livre e surge no Brasil muito semelhante à escola de Frankfurt, na Alemanha. Para Althusser (1985) e Bourdieu (2004) a pedagogia crítica orinda dessa teoria (pedagogia crítica-reprodutivista) não traz componentes curriculares que possibilitem a emancipação do sujeito, pois elimina os componentes críticos

DOI: Em andamento. 
reflexivos no currículo, para formar mão de obra especializada, criando indivíduos passivos que se submetem a opressão da classe dominante.

A teoria pós-crítica vai tomando "forma à medida que diferencia no bojo das concepções críticas; ela diferencia-se da visão crítico-reprodutivista, uma vez que procura articular um tipo de orientação pedagógica que seja crítica sem ser reprodutivista" (SAVIANI, 2005, p. 65).

"A pedagogia histórico-crítica defende uma organização curricular com base em áreas de conhecimento nas quais as múltiplas dimensões de conteúdos sejam integradas e inter-relacionadas entre si, despertando uma análise crítica e reflexiva nos educandos. Enfatiza que os conteúdos universais e culturais devem ser trabalhados com base nas relações diretas de experiências trazidas da realidade social e confrontadas com o conhecimento sistematizado" (LIMA; ZANLORENZI; PINHEIRO, 2011, p. 94).

No quadro 1 figuram as escolas teóricas estudadas e respectivos currículos por elas adotadas.

Quadro 1 - Relação entre escola teórica e currículo

\section{Escola Teórica Currículo}

\begin{tabular}{|l|l|}
\hline Teorias Acríticas & $\begin{array}{l}\text { A organização curricular enfatiza a quantidade de conteúdos, que são } \\
\text { apresentados de forma fragmentada, estanque, descontextualizada e sem } \\
\text { articulação com a realidade prática. Nesse contexto, o professor é o } \\
\text { detentor do saber e o educando é um ser passivo, que apenas retém as } \\
\text { informações transmitidas na sala de aula, memorizando o conteúdo por } \\
\text { meio de repetidas atividades de fixação. }\end{array}$ \\
\hline Teoria Crítica & $\begin{array}{l}\text { O currículo é elaborado a partir da preocupação com a formação da } \\
\text { identidade dos indivíduos e de acordo com os significados sobre a realidade } \\
\text { expressa nos discursos desses indivíduos. }\end{array}$ \\
\hline Teoria Pós-critica & $\begin{array}{l}\text { O currículo não é entendido, nem trabalhado como um conglomerado de } \\
\text { disciplinas isoladas, mas transcende o modelo reprodutivista de organização } \\
\text { curricular para adequar-se às necessidades da atual sociedade. }\end{array}$ \\
\hline
\end{tabular}

Fonte: Elaborado a partir de Lima; Zanlorenzi; Pinheiro (2011).

Para Paulo Freire (1987, p. 68) "ninguém educa ninguém" e, portanto, é presunçoso imaginar que alguém educa outro alguém e em virtude disso, aplicar a si próprio o termo de educador (Teorias Acríticas). Mas Paulo Freire acrescenta também, que "ninguém educa a si mesmo, os homens se educam entre si, mediatizados pelo mundo", segundo o autor, os 
indivíduos se educam a si próprios, na justa medida em que interagem com outros, trocam ideias, discutem, colaboram, cooperam, apoiam (Teoria Crítica).

O objetivo da educação, seja ela presencial ou à distância, é conseguir que um indivíduo que nasce dependente e que por si só, por mero processo de crescimento e amadurecimento não se tornaria um ser humano adulto autônomo, se torne um sujeito emancipado (Teoria Póscrítica). Isso só é possível porque o ser humano é capaz de aprender, tem a capacidade inata de em interação com outros seres humanos desenvolver habilidades e competências necessárias à sua emancipação.

"De todo modo, o ponto focal da educação superior - seja ela presencial ou à distância, nas inúmeras combinações possíveis entre presença, presença virtual $e$ distância - é o desenvolvimento humano, em uma perspectiva de compromisso com a construção de uma sociedade socialmente justa. Daí a importância da educação superior ser baseada em um projeto pedagógico e em uma organização curricular inovadora, que favoreçam a integração entre os conteúdos e suas metodologias, bem como o diálogo do estudante consigo mesmo (e sua cultura), com os outros (e suas culturas) e com o conhecimento historicamente acumulado" (BRASIL, 2007, p. 9, grifo nosso).

Embora muito se tenha avançado em termos de educação do perído Jesuítico até os dias de hoje, a prática pedagógica Brasileira apresenta resquícios da pedagogia tradicional e tecnicista. Depreende-se que essa situação é fruto de um sistema avaliativo quantitativo. Importante enfatizar que a avaliação periódica proposta no governo de Fernando Henrique Cardoso (FHC) ainda é vigente. As escolas concentram esforços para garantir a inserção dos seus alunos no Ensino Superior e uma vez universitários esses alunos são submetidos ao Exame Nacional de Desempenho dos Estudantes (ENADE) que tem como objetivo "aferir o desempenho dos estudantes em relação aos conteúdos programáticos previstos nas diretrizes curriculares do respectivo curso de graduação e as habilidades e competências em sua formação", (BRASIL, 2014, grifo nosso) o que acaba evidentemente, remetendo a proposta curricular da escola tradicional e tecnicista.

Com tantas metas a cumprir, as instituições de ensino perdem o foco no que é primordial, munir o aluno com conhecimentos que auxiliem em sua compreensão sobre as complexas relações da vida cotidiana. Desta forma, falar em EAD não implica em se ater a palavra "distância", mas sim no processo educativo que envolve uma abordagem contextualizada da realidade atual.

\section{Material educacional digital}


Comenius, pedagogo do século XVII, inquieto com o problema epistemológico do método educativo, escreveu em 1627 a Didáctica Checa, tendo sido denominada Didática Magna após sua tradução para o latim, em 1631, cuja finalidade era criar um método universal para ensinar tudo a todos. Nesta perspectiva histórica a palavra didática foi cunhada como uma tecnologia que possibilitaria ensinar tudo a todos ou traduzido do grego didatiké a arte de ensinar.

Em consequência disso "a didática quando aplicada a um material, implica em um conjunto sistemático de princípios, normas, recursos e procedimentos dos conteúdos programados, de forma a conduzir de modo consciente e responsável o processo de aprendizagem do educando" (SILVA, 2013, p. 66). O material para a EAD requer outra lógica de concepção em relação ao material concebido para a educação presencial. O material elaborado para a EAD necessita de uma equipe multidisciplinar que seja capaz de trabalhar com a mediação do processo ensino-aprendizagem. "Cabe observar que somente a experiência com cursos presenciais não é suficiente para assegurar a qualidade da produção de materiais adequados para a educação à distância" (BRASIL, 2007, p. 13).

Sem digressão algumas questões vêm à tona: Como aprender e ensinar a distância? A sala de aula ainda é o espaço mais importante para a construção do conhecimento? Para Oliveira (2010, p. 146) as aulas "podem ocorrer fora dos portões da universidade e das salas de aula convencionais sem deixar de ser aula. Isso significa que a sala de aula é um espaço físico dinamizado pela ação pedagógica", mas que não é o único espaço de ação educativa, nem o único espaço em se pode lançar mão de recursos didáticos e midiáticos para mediar à aquisição de conhecimento.

\begin{abstract}
"Os recursos digitais [...] surgem como uma ferramenta capaz de potencializar a reestruturação de práticas pedagógicas, originando novas formas de pensar a respeito do uso da comunicação, da ciência da informação, da construção, do conhecimento e da sua integração com a realidade. Desse modo, surgem os materiais educacionais digitais (MEDS) [...]. Porém, a utilização da tecnologia pela tecnologia não é o suficiente para a contemplação de uma nova concepção educacional. O diferencial está no planejamento pedagógico em que esses recursos digitais estão inseridos. Será preciso contemplar uma pedagogia baseada na pesquisa, no acesso a informação, na complexidade, na diversidade e na imprevisibilidade, de modo a possibilitar a criação de novos ambientes cognitivos" (BEHAR, 2009, p. 33).
\end{abstract}

Como por muito tempo a referência em educação que a sociedade conhecia era a sala de aula (física) tradicional, é natural que os primeiros materiais educacionais digitais (MEDS) fossem uma simples transposição dos métodos tradicionais de ensino. Certamente, pode-se considerar que no início da EAD ela esteve mais voltada à utilização das tecnologias da informação e 
comunicação (TICS), do que na sua concreta efetivação, do ponto de vista da aprendizagem do aluno.

Em 1985, 358 anos após Comenius ter escrito a Didática Magna, Chevallard apresenta a Teoria da Trasposição Didática: Un contenu de savoir ayant été designé comme savoir à enseigner subit dés lors un ensemble de transformations adaptatives qui vont le rendre apte à prendre place parmi les objets dénseignement. Le travail qui d'un objet de savoir à enseigner fait un objet d'enseignement est appelé la transposition didactique", em português "Um conteúdo a ser ensinado, sofre um conjunto de transformações adaptativas que irão torná-lo apto a ocupar um lugar entre os objetos de ensino, a técnica para transformar esse conteúdo que será ensinado em um objeto de ensino, é chamada transposição didática" (CHEVALLARD, 1991, p. 39, tradução nossa).

A partir dessa teoria, a relação educativa em sala de aula deixa de ser binária, professor/aluno, para se tornar ternária, professor/aluno/conteúdo. Na concepção do material didático para a EAD a transposição didática é fundamental, decerto deve-se contar com uma equipe especializada para realizar a transposição didática do conteúdo para os MEDS.

"Há uma grande preocupação em relação ao material didático, pois na EAD o material didático é um dos elementos mediadores importantes que traduz a concepção pedagógica e que auxilia no processo ensino aprendizagem. Deve, portanto ser construido de acordo com o projeto pedagógico do curso, refletindo sua concepção pedagógica. A concepção de cursos à distância e seus materiais didáticos são complexos desafios e as bases conceituais norteadoras das propostas determinantes de sua qualidade (BRITO; BELÃO, 2012, p.83, grifo nosso)."

Para Behar (2009) são quatro os parâmetros para construção de MEDS que devem ser levados em consideração. No quadro 2 figuram quais são esses parâmetros e suas respectivas aplicações. 
Quadro 2 - Parâmetros para construção de MEDS

\begin{tabular}{|c|c|c|}
\hline \multirow[t]{2}{*}{ Parâmetros } & \multicolumn{2}{|c|}{ Aplicações } \\
\hline & Com relação ao conteúdo & Com relação a interface \\
\hline Imagem & $\begin{array}{l}\text { Apoio a práticas pedagógicas; } \\
\text { Utilizar imagens estáticas e interativas, } \\
\text { para teste de hipóteses. }\end{array}$ & $\begin{array}{l}\text { Contextualizar a interface no assunto } \\
\text { abordado; } \\
\text { Utilizar icones de alta iconicidade. }\end{array}$ \\
\hline Navegação & $\begin{array}{l}\text { Escolher o tipo de navegação: linear, } \\
\text { não linear, mista, breadcrumbs } \\
\text { (caminhos de migalhas de pão); } \\
\text { Contemplar: Visibilidade; feedback; } \\
\text { mapeamento e consistência. }\end{array}$ & $\begin{array}{l}\text { Contemplar a usabilidade: Condução; } \\
\text { Carga de trabalho; Controle explícito; } \\
\text { Adaptabilidade; Gestão de erros; } \\
\text { Consistência; } \quad \text { Expressividade; } \\
\text { Compatibilidade. }\end{array}$ \\
\hline $\begin{array}{l}\text { Interação e } \\
\text { Interatividade }\end{array}$ & \multicolumn{2}{|c|}{$\begin{array}{l}\text { Três modelos conceituais: } \\
\text { 1. Baseado em atividades (instrução, conversação, manipulação e navegação, } \\
\text { exploração e pesquisa); } \\
\text { 2. Baseado em objetos (interface remete a objetos comuns do cotidiano); } \\
\text { 3. Mistas (integrar atividades e objetos). }\end{array}$} \\
\hline $\begin{array}{l}\text { Organização } \\
\text { do Conteúdo }\end{array}$ & \multicolumn{2}{|c|}{$\begin{array}{l}\text { Planejar o conteúdo de forma a possibilitar o diálogo entre o usuário e a teoria } \\
\text { abordada. } \\
\text { 1. Relação de ajuda: instigar os alunos com desafios; } \\
\text { 2. Relativização do Discurso: Possibilitar que o usuário atue criticamente sobre } \\
\text { o conteúdo. }\end{array}$} \\
\hline
\end{tabular}

Fonte: Adaptado de Behar (2009).

No parâmetro imagem, a partir da figura 2, é possível verificar duas versões de material didático elaborado para um curso de formação de professores. A tela colada ao lado esquerdo da figura possue um apelo maior, pois contempla uma charge do cartunista Maurício de Souza, cuja metáfora remete o professor ao seu cotidiano, coadunando com uma das características da teoria 
crítica, que apresenta os conteúdos curriculares com base nas experiências de vida do sujeito. A charge neste caso contextualiza o assunto abordado no curso, torna o conteúdo mais atrativo e significativo para o público a que se destina e possibilita ao leitor atribuir novos significados ao texto.

Na tela colada ao lado direito da figura, foi extraída a charge para demonstrar que o mesmo conteúdo, porém sem imagem, tornar-se menos atraente ao leitor. A imagem é uma possibilidade convencional de comunicação e sua homogeneidade facilita a interação.

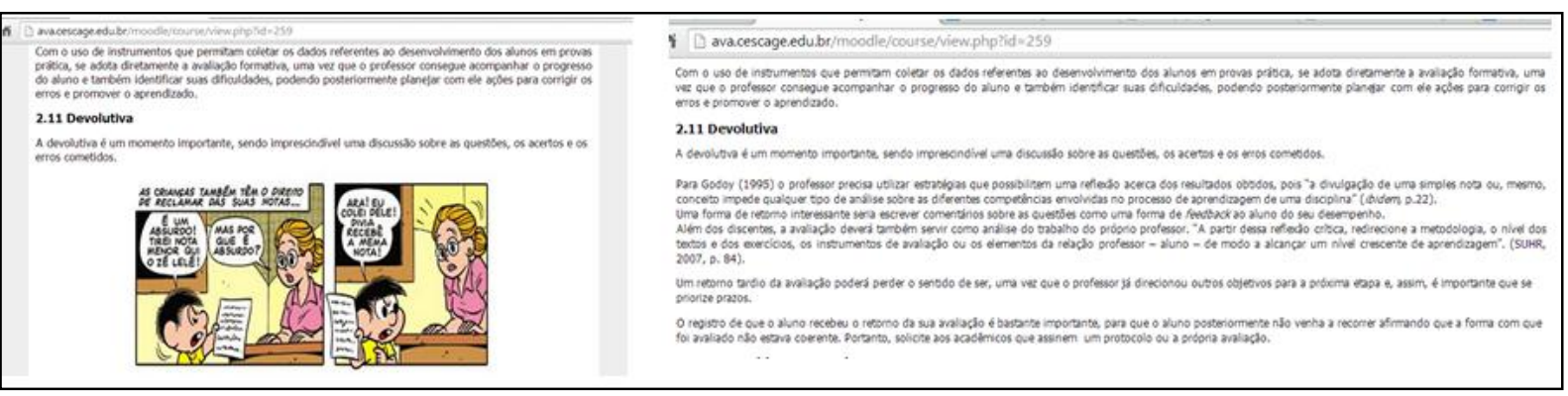

Figura 2 - Parâmetro imagem

(Fonte: Curso para formação de professores (CESCAGE, 2014)).

Um exemplo do parâmetro navegação, item usabilidade, aparece na figura 3. Ao lado esquerdo da figura a tela da web tem elementos, ícones, que indicam claramente qual ação o usuário deve realizar para atingir determinado fim e ao lado direito da figura aparece à mesma tela, porém sem esses elementos. $O$ único elemento que pode ser considerado indicador na tela a direita é o ícone verde onde se lê "novo item", entretanto o usuário não tem explicações suficientes para saber o que estará criando, podendo gerar confusão e estresse no usuário.

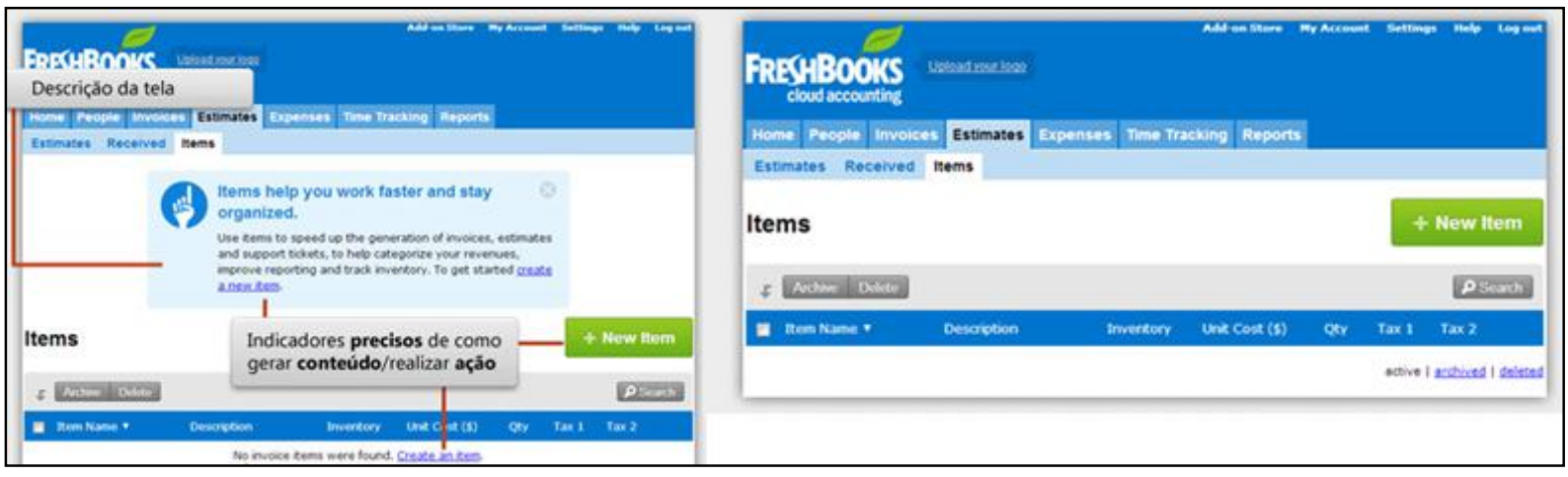

Figura 3 - Parâmetro navegação

(Fonte: http://codigofonte.uol.com.br/artigos/ Acesso em 02 de julho de 2014.)

DOI: Em andamento. 
Para ilustrar o parâmetro interação e interatividade, vamos recorrer à definição da Beloni (2009, p.58):

"É fundamental esclarecer com precisão a diferença entre o conceito sociológico de interação - ação recíproca entre dois ou mais atores onde ocorre a intersubjetividade, isto é, encontro de dois sujeitos - que pode ser direta ou indireta (mediatizada por algum veículo técnico de comunicação, por exemplo, carta ou telefone); e a interatividade, termo que vem sendo usado indistintamente com dois significados diferentes em geral confundidos: de um lado a potencialidade técnica oferecida por determinado meio (por exemplo: CD-ROMS de consulta, hipertextos em geral, ou jogos informatizados) e, de outro, a atividade humana, do usuário de agir sobre a máquina, e de receber em troca uma "retroação" da máquina sobre ele (BELONI, 2009, p. 58)."

$\mathrm{Na}$ esteira de que o processo ensino-aprendizagem se constrói pela interação entre o sujeito cognoscente e o objeto cognoscível e que na EAD essa relação acontece permeada pelas TICS, que surgem para possibilitar a comunicação e a transferência de informação entre pessoas dispersas no espaço e no tempo, é coerente afirmar que a escolha e o uso adequado desta, permitem minimizar algumas limitações conhecidas na EAD, como a falta de interação e o isolamento do aluno do processo educativo.

A figura 4 é cópia da tela de abertura de um jogo de história on line chamado "Império", que é baseado em atividades de instrução, manipulação, navegação, conversação, exploração e pesquisa em que há total interatividade entre máquina e usuário, também há interação com jogadores que estão dispersos geograficamente.

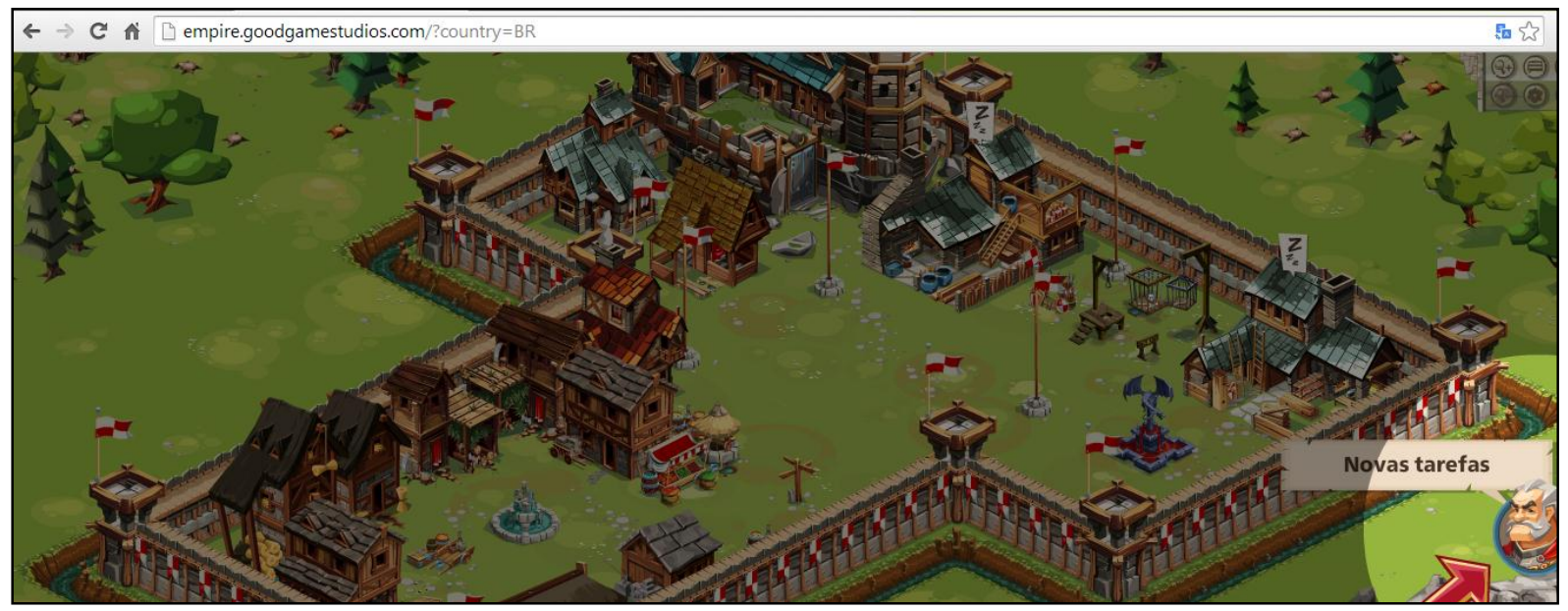

Figura 4 - Parâmetro interação e interatividade

(Fonte: http://empire.goodgamestudios.com/?country=BR. Acesso em 02 de julho de 2014.) 
O parâmetro organização do conteúdo na plataforma é um elemento norteador de como o aluno pode construir seu conhecimento, sobre como ocorrerá o processo ensino-aprendizagem. É também um dos parâmetros mais fáceis para identificar qual a concepção de educação adotada, pois a forma como o currículo é trabalhado remete as escolas teóricas ora apresentadas. 0 material não deve conter mensagem explícita ou implícita de convencimento para o aluno acessálo ou qual caminho percorrer, ao contrário, deve estar exposto de tal forma que o aluno tenha autonomia sobre o mesmo. Desta forma há possibilidade que o aluno reflita criticamente, seja sujeito do aprendizado e interaja com o material, com os alunos, professores e tutores.

Na figura 5, foram coladas duas telas de cursos para formação de professores, ambos os cursos trabalham com conteúdos modulares. $O$ curso representado na tela da esquerda apresenta os módulos através de "abas", de tal maneira que o aluno pode navegar pelo curso/conteúdo todo, tão logo esteja "logado" no ambiente. Esta forma de organização curricular é fruto de uma concepção de educação pós-crítica, pois transcende o modelo reprodutivista de currículo para adequar-se as necessidades da sociedade atual, tendo em vista que o conteúdo não é trabalhado como um aglomerado de disciplinas sequenciais, seguidas logicamente.

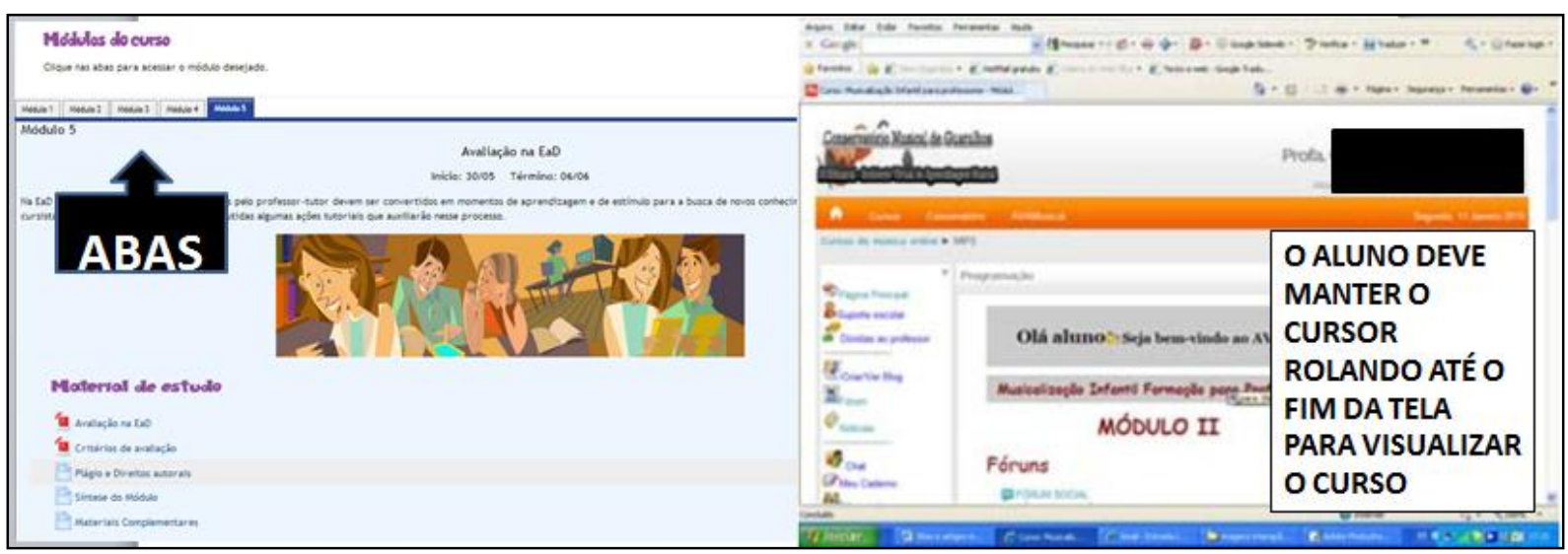

Figura 5: Parâmetro organização do conteúdo

Fonte: Cursos para formação de tutores (PARANÁ, 2014)

$\mathrm{Na}$ tela ao lado direito o aluno precisa manter o cursor rolando para visualizar o curso/conteúdo completo. Quando a organização do conteúdo mantem esse padrão linear, pode transmitir ao aluno a mensagem de que ir ao final do curso e realizar a última atividade pode ser uma transgressão as regras impostas, por exemplo. Esta forma de organizar o conteúdo remete a concepção tradicional de ensino, aonde os alunos precisam seguir as tarefas sequencialmente de maneira passiva, apenas retendo as informações que lhe são transmitidas. É óbvio que a disposição do conteúdo na plataforma também depende de um bom programador, que esteja

DOI: Em andamento. 
alinhado com a concepção de ensino da instituição e que possua as habilidades técnicas necessárias para proceder à programação.

"O Material Didático, tanto do ponto de vista da abordagem do conteúdo, quanto da forma, deve estar concebido de acordo com os princípios epistemológicos, metodológicos e políticos explicitados no projeto pedagógico, de modo a facilitar a construção do conhecimento e mediar a interlocução entre estudante e professor, devendo passar por rigoroso processo de avaliação prévia (pré-testagem), com o objetivo de identificar necessidades de ajustes, visando o seu aperfeiçoamento" (BRASIL, 2007, p. 13).

A escolha do modelo conceitual para o desenvolvimento dos MEDS está atrelada ao público alvo e ao objetivo do curso. $O$ ideal é escolher um modelo de material híbrido, alicerçando o contexto e o cenário do processo ensino-aprendizagem e acima de tudo é importante que o aluno ao se deparar com materiais de um curso a distância saiba exatamente o que fazer.

Conforme visto e de acordo com o $\S 1$ 을 dos Referencias de Qualidade para Educação Superior a Distância "A educação a distância organiza-se segundo metodologia, gestão e avaliação peculiares [...]" (BRASIL, 2007, grifo nosso). Peculiar significa que é próprio; inerente de alguém ou de alguma coisa; que constitui o atributo de alguém ou alguma coisa, entretanto, na literatura pertinente a EAD não se encontra concepções de ensino diferenciadas, "peculiares" da empregada na educação presencial, o que sofre alteração é o suporte tecnológico.

\section{Considerações finais}

Foi verificado neste estudo que não existe fórmula para a construção de MEDS e que cada instituição de ensino deve criar um modelo para sua implantação. No que tange à contribuição das concepções de educação e currículo para a construção de MEDS este estudo apresenta indícios que dão suporte a ideia de que o ideal é a concreta possibilidade de através da transposição didática do conteúdo privilegiar uma forma crítica de educação que ultrapasse o modelo curricular reprodutivista.

A efetividade da EAD não depende unicamente do método de ensino escolhido pela IES, depende da concepção educacional que originou o método e dos MEDS empregados para a viabilização deste. $\mathrm{O}$ ideal é escolher um modelo híbrido, alicerçando o contexto e o cenário do processo ensino-aprendizagem e acima de tudo é importante que o aluno ao se deparar com materiais de um curso a distância saiba exatamente o que fazer. É essencial que o material seja bem elaborado e não ofereça obstáculos, tanto de ordem tecnológica como de ordem pedagógica, sendo construído por equipes multidisciplinares bem preparadas na área de produção de materiais para torná-lo o mais atraente possível, evitando o excesso de hipertextos e caminhos virtuais que possam confundir o aluno.

98 DOI: Em andamento.

R. Bras. de Ensino de C\&T 
A conclusão aponta ainda que é alta a importância da utilização das teorias de educação, especialmente a teoria histórico crítica, para a construção de materiais digitais para a EAD. Indica também a viabilidade da utilização destas teorias para a ampliação e qualidade de MEDS, bem como o desvelamento das concepções que por muitas vezes são contraditórias com a prática e podem representar uma barreira para o alcance dos objetivos da educação, seja ela presencial ou não.

\section{Referências}

ALTHUSSER, Louis. Aparelhos ideológicos do estado. Rio de Janeiro: Graal, 1985.

BEHAR, Patrícia Alejandra (orgs). Modelos Pedagógicos em Educação a Distância. Porto Alegre: Artmed, 2009.

BELLONI, Maria Luiza. Educação a Distância. Campinas. Editores Associados, 2009.

BOURDIEU, Pierre. O poder simbólico. 7 ed. Rio de Janeiro: Bertrand Brasil, 2004.

BRASIL. Instituto Nacional de Estudos e Pesquisas Educacionais Anísio Teixeira. Disponível em http://portal.inep.gov.br/ . Acesso em 01 de julho de 2014.

Lei de Diretrizes e Bases para a Educação Nacional. Lei no 9.394, de 20 de dezembro de 1996. Diário Oficial da União. Ministério da Educação: Brasília, 1996.

Referenciais de Qualidade para Educação Superior a Distancia. Diário Oficial da União. Ministério da Educação, Secretaria de Educação a Distância: Brasília, 2007.

BRITO, Glaucia da Silva; BELÃO, Vanessa do Rocio Godoi Garrett. A utilização de material didático impresso na educação a distância do século XXI. In: BRITO, Glaucia da Silva (org.). Cadernos de Educação a Distância. Curitiba, UFPR, 2012. p. 77-90.

CHEVALLARD, Yves. La Transposition Didactique: Du Savoir Savant au Savoir Ensigné. Grenoble: La pensée Sauvage, 1991.

CUNHA, Marcus Vinicius; SOUZA, Aline Vieira de Souza. Cecília Meireles e o temário da Escola Nova. Cadernos de Pesquisa, vol.41(144), p.850-865, dez, 2011.

FREIRE, Paulo. Pedagogia do Oprimido. 39 ed. Rio de Janeiro: Paz e Terra, 1987.

GASPARIN, João Luiz. Uma Didática para a Pedagogia Histórico Crítica. 3. ed. Campinas: Autores Associados, 2005.

LIMA, Michelle Fernandes; ZANLORENZI, Claudia Maria Petchak; PINHEIRO, Luciana Ribeiro. A função do currículo no contexto escolar. Curitiba: IBPEX, 2011.

OLIVEIRA, Diene Eire de Mello Bortotti de. Educação à distância: a reconfiguração dos elementos didáticos. Tese (Doutorado em Educação). Universidade Estadual de Maringá. Maringá, 2010.

R. B. E. C. T., vol 8, Ed. Sinect, jan-abr.2015 ISSN - 1982-873X

DOI: Em andamento. 
SAVIANI, Dermeval. História das ideias pedagógicas no Brasil. 3. ed. Campinas: Autores Associados, 2011.

Pedagogia Histórico-Crítica. 9. ed. Campinas: Autores Associados, 2005.

SILVA, Andreza Regina Lopes da. Diretrizes de design instrucional para elaboração de material didático em EAD. Dissertação (Mestado em Engenharia e Gestão do Conhecimento). Universidade Federal de Santa Catarina. Florianópolis, 2013.

SOUTO, Romélia Mara Alves; PAIVA, Paulo Henrique Apipe Avelar. A pouca atratividade da carreira docente: um estudo sobre o exercício da profissão entre egressos de uma Licenciatura em Matemática. Pro-Posições, v. 24, n.1 (70), p. 201-224, jan./abr, 2013.

Antonella Carvalho de Oliveira - Doutoranda em Ensino de Ciência e Tecnologia - Programa de Pós-Graduação em Ensino de Ciência e Tecnologia (PPGECT). Universidade Tecnológica Federal do Paraná/UTFPR - Campus Ponta Grossa. antonella 0611@hotmail.com

Antonio Carlos Frasson - Doutor em Educação. Professor do Programa de Pós-Graduação em Ensino de Ciência e Tecnologia (PPGECT) - Universidade Tecnológica Federal do Paraná/UTFPR Campus Ponta Grossa. ancafra@gmail.com 